\title{
Empirical correlations for viscosity of partially hydrolyzed Polyacrylamide
}

\author{
Changhong Gao
}

Received: 19 February 2013 / Accepted: 19 May 2013/Published online: 7 June 2013

(C) The Author(s) 2013. This article is published with open access at Springerlink.com

\begin{abstract}
During water flooding operations, polymer can be added to injected water to improve sweep efficiency and retard viscous fingering. This technique, namely polymer flooding has achieved successful large-scale field applications in China. Polymer flooding is also being tested in several heavy oil fields. For oil field applications, partially hydrolyzed polyacrylamide (HPAM) is the most widelyused polymer. HPAM solution must maintain high viscosity to effectively mobilize oil. In reality however, polymer is very sensitive to salinity and hardness of base water and underground water. This phenomenon is studied in this paper. The two HPAM test samples have molecular weight of 10 million and 20 million Dalton. The first group of tests was conducted to study the effect of salinity on HPAM viscosity. The second group of tests was carried out to evaluate the effect of hardness on HPAM viscosity. It was discovered that both sodium and calcium ions can severely damage polymer viscosity. Data analysis shows that the empirical non-Newtonian parameters are strong functions of water salinity and hardness. Based on test data, empirical formulas are proposed to calculate HPAM viscosity influenced by polymer concentration, temperature, water salinity and water hardness. These formulas are useful tools for predicting HPAM viscosity in field applications.
\end{abstract}

Keywords HPAM · Viscosity · Salinity · Hardness · Degradation · Power law

C. Gao $(\bowtie)$

Sinopec Shengli Oil Field Company, Dongying, China e-mail: 237184689@QQ.COM

\section{Introduction}

During oil and gas production, water is often injected into reservoirs to sweep oil to the production well. Because oil viscosity is often much higher than water viscosity, injected water moves faster than oil, leaving oil behind. This phenomenon is referred to as viscous fingering. Polymer can be added to injected water to retard viscous fingering. Polymer increases the viscosity of injected water, reduces water mobility, and therefore achieves a more stable displacement (Littmann 1988).

Polymer flooding has become the most successful chemical method for enhanced oil recovery (EOR). For the Daqing oil field in China, polymer flooding has contributed to more than $10 \%$ of EOR (Wang et al. 2009). For field applications, partially hydrolyzed polyacrylamide (HPAM) is the most widely used polymer, thanks to its relatively cheap price and good solubility in water. The molecular structure of HPAM is given in Fig. 1 (Sheng 2010).

Polymer solution must maintain high viscosity to mobilize oil in reservoir. However, high shearing, high temperature, high salinity and hardness often exist in oil reservoirs and production systems. The polymer can severely degrade under these harsh conditions, which is the major issue facing polymer flooding operation (Gao 2011).

HPAM degradation has been studied for many years. In an early study, it was observed that $\mathrm{NaCl}, \mathrm{CaCl}_{2}$ and $\mathrm{MgCl}_{2}$ depressed HPAM viscosity, and HPAM was very sensitive to divalent ions (Mungan 1972). These findings were confirmed by other studies (Maerker 1975; Ward and Martin 1981; Ryles 1988). Therefore it is not a surprise that most successful field applications of polymer flood were carried out in low-salinity reservoirs (Needham and Doe 1987). Moreover, shearing and thermal degradation also have negative impacts on viscosity of HPAM (Gao 2013).

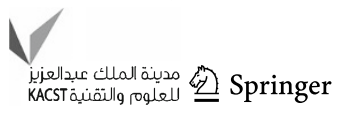




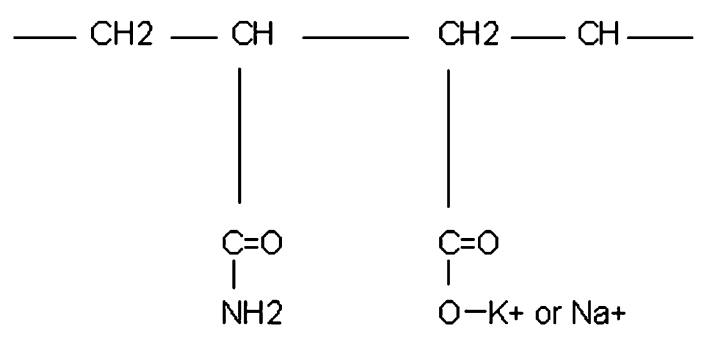

Fig. 1 Structure of HPAM

Polymer solution is a non-Newtonian fluid that follows the power law given in Eq. 1, where $\mu$ is the viscosity (cP), $\gamma$ is the shear rate $(1 / \mathrm{s}), k$ is the consistency index, and $n$ is the flow behavior index (Rabia 1985). More complex models were also developed to describe polymer viscosity more accurately, such as the Ellis model and Carreau model (Sochi 2009).

$\mu=k \gamma^{n}$

It has to be pointed out that the previous models failed to quantify the influence of individual factors on polymer viscosity. As a result, it is still a challenge to correctly predict the viscosity of HPAM under the complex underground environment. In recent years, polymer flood attracted largescale field applications in China (Sheng 2010). However, the change in polymer viscosity while HPAM flows through injection facilities and underground rocks has to rely on frequent sampling. There is no reliable formula to predict the viscosity behavior of HPAM in oilfield applications.

This paper obtains polymer viscosity data through laboratory testing. The author also attempts to build numerical correlations for viscosity of HPAM solution. The proposed correlations take into account the various factors that affect polymer viscosity. This work improves the prediction of polymer viscosity in underground environment.

\section{Materials and methods}

HPAM is the most widely used polymer product for EOR projects. Recent EOR projects employed HPAM products with high molecular weights. Two HPAM samples, coded as 3,100 and 3,200, were supplied by a polymer producer in the form of powders. The molecular weight of product 3,100 was around 10 million Dalton, and that of product 3,200 was 20 million. For both the products, the degree of hydrolysis was around $25 \%$.

For the first group of tests, polymer powder was added to $\mathrm{NaCl}$ brine to result in a concentration of $1,500 \mathrm{ppm}$. The concentration of $\mathrm{NaCl}$ ranged from 0.1 to $3 \%$ by weight. The polymer solution was stirred for $48 \mathrm{~h}$ to ensure good mixing. Polymer viscosity was then measured at $50{ }^{\circ} \mathrm{C}$ under varied shear rates with a torque-type viscometer.
The second group of tests was to study the effect of calcium ions on polymer viscosity. The base brine contains sodium chloride and calcium chloride. The concentration of $\mathrm{NaCl}$ was controlled at $1 \%$ by weight. The concentration of $\mathrm{CaCl}_{2}$ ranged from 0.05 to $0.15 \%$ by weight. Polymer powder was added to $\mathrm{NaCl}$ and $\mathrm{CaCl}_{2}$ brine to result in a concentration of $1,500 \mathrm{ppm}$. The polymer viscosity was then measured at $50{ }^{\circ} \mathrm{C}$ under varied shear rates.

\section{Experimental results}

The viscosity data for the product 3,100 in $\mathrm{NaCl}$ brine are given in Fig. 2. The viscosity data for the product 3,100 in $\mathrm{CaCl}_{2}$ brine are given in Fig. 3. These trends comply with the power law. Similar test results on the product 3,200 were obtained, but not presented here. It is obvious that both $\mathrm{NaCl}$ and $\mathrm{CaCl}_{2}$ severely damage the HPAM viscosity, while HPAM is more sensitive to calcium concentration.

\section{Model formulation and validation}

By curve fitting, the power law parameters for the two groups of tests are obtained, as presented in Tables 1, 2. Figures 4, 5 plot the relationships between the power-law parameters and the $\mathrm{NaCl}$ concentration $\left(C_{\mathrm{Na}}\right.$, wt \%). It can be seen that the parameter $k$ is depressed at high salinity, while the parameter $n$ slightly increases at elevated salinity. It is obvious that the two HPAM products follow similar trends. The generalized relationship can be expressed as Eqs. (2), (3), where $a, a 1, \alpha$, and $\alpha 1$ are empirical parameters.

$\ln (k)=a \times \ln \left(C_{\mathrm{Na}}\right)+a 1$

$n=\alpha \times \ln \left(C_{N a}\right)+\alpha 1$

Figures 6, 7 plot the relationships between the powerlaw parameters and the $\mathrm{CaCl}_{2}$ concentration $\left(C_{\mathrm{Ca}}\right.$, wt $\left.\%\right)$.

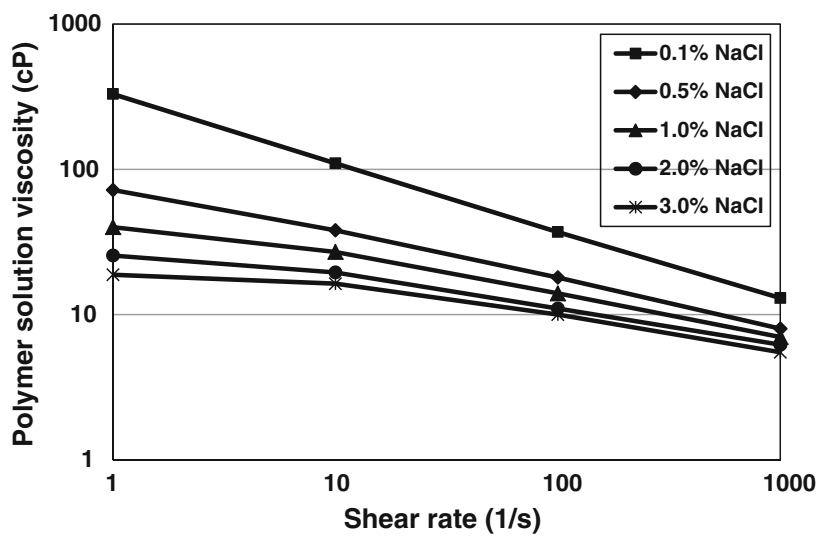

Fig. 2 Viscosity data for the product 3,100 in $\mathrm{NaCl}$ solutions 


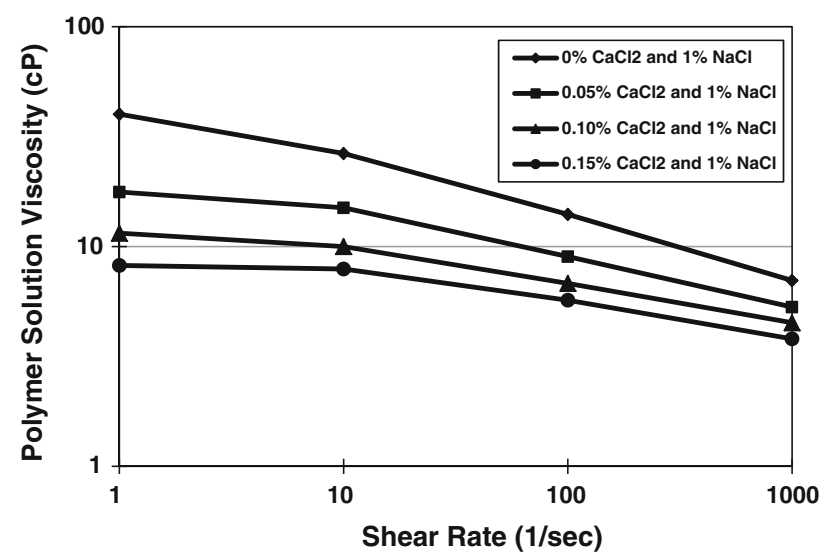

Fig. 3 Viscosity data for the product 3,100 in $\mathrm{CaCl}_{2}$ solutions

Table 1 Power law parameters for tests in $\mathrm{NaCl}$

\begin{tabular}{llllll}
\hline $\begin{array}{l}\text { Polymer } \\
\text { product }\end{array}$ & $\begin{array}{l}\mathrm{NaCl} \\
(\mathrm{wt} \%)\end{array}$ & $\begin{array}{l}k \\
\text { (tested) }\end{array}$ & $\begin{array}{l}k \\
\text { (calculated) }\end{array}$ & $\begin{array}{l}n \\
\text { (tested) }\end{array}$ & $\begin{array}{l}n \\
\text { (calculated) }\end{array}$ \\
\hline 3,100 & 0.5 & 75.33 & 73.88 & -0.319 & -0.315 \\
& 2.0 & 27.94 & 30.85 & -0.209 & -0.221 \\
& 3.0 & 21.32 & 19.93 & -0.181 & -0.173 \\
3,200 & 0.5 & 189.80 & 171.83 & -0.384 & -0.405 \\
& 2.0 & 65.18 & 71.65 & -0.350 & -0.361 \\
& 3.0 & 50.72 & 55.48 & -0.331 & -0.339 \\
\hline
\end{tabular}

Table 2 Power law parameters for tests in $\mathrm{CaCl}_{2}$

\begin{tabular}{llllll}
\hline $\begin{array}{l}\text { Polymer } \\
\text { product }\end{array}$ & $\begin{array}{l}\mathrm{CaCl}_{2} \\
(\mathrm{wt} \%)\end{array}$ & $\begin{array}{l}k \\
\text { (tested) }\end{array}$ & $\begin{array}{l}k \\
\text { (calculated) }\end{array}$ & $\begin{array}{l}n \\
\text { (tested) }\end{array}$ & $\begin{array}{l}n \\
\text { (calculated) }\end{array}$ \\
\hline 3,100 & 0.05 & 19.70 & 18.50 & -0.179 & -0.179 \\
& 0.10 & 12.45 & 12.47 & -0.139 & -0.142 \\
& 0.15 & 9.10 & 9.22 & -0.114 & -0.113 \\
3,200 & 0.05 & 40.99 & 43.22 & -0.265 & -0.277 \\
& 0.10 & 30.48 & 29.24 & -0.236 & -0.233 \\
& 0.15 & 21.88 & 21.67 & -0.198 & -0.199 \\
\hline
\end{tabular}

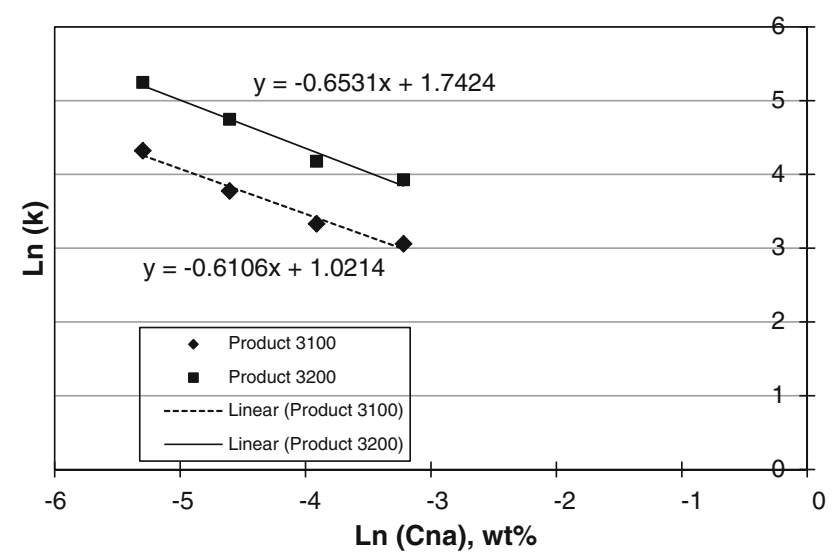

Fig. 4 Relationship between $\mathrm{NaCl}$ concentration and parameter $k$

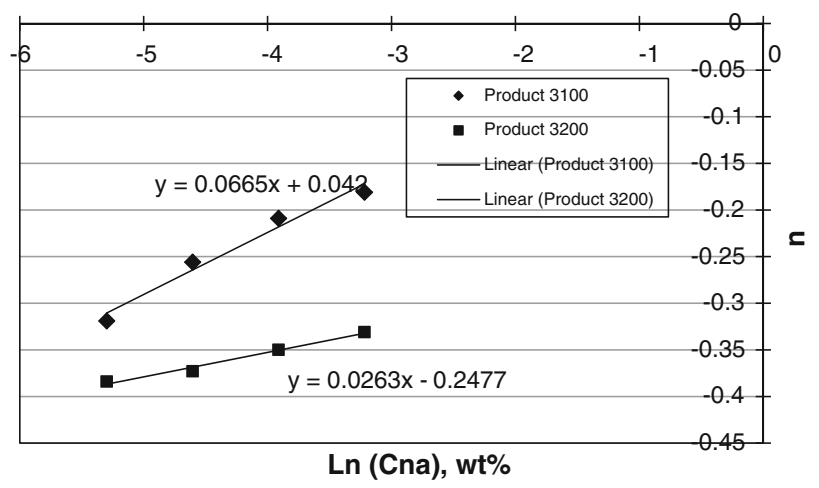

Fig. 5 Relationship between $\mathrm{NaCl}$ concentration and parameter $n$

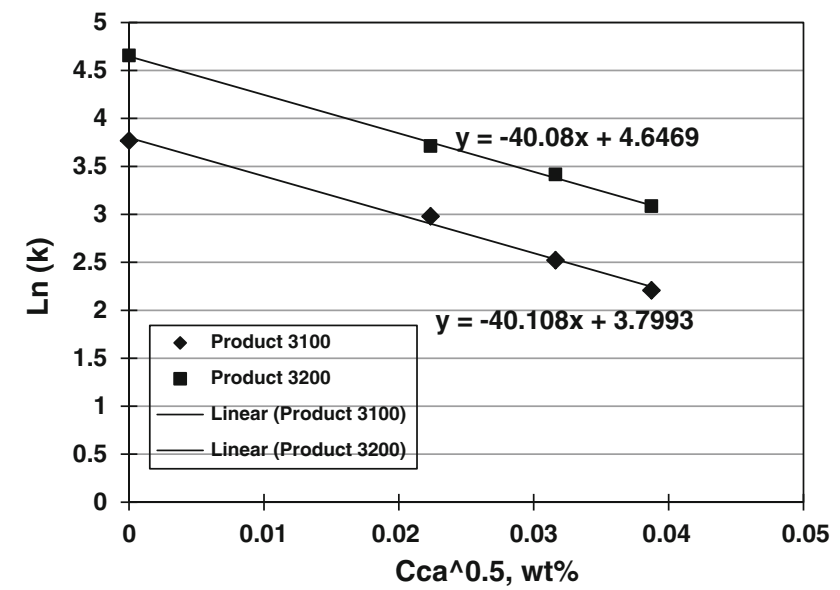

Fig. 6 Relationship between $\mathrm{CaCl}_{2}$ concentration and parameter $k$

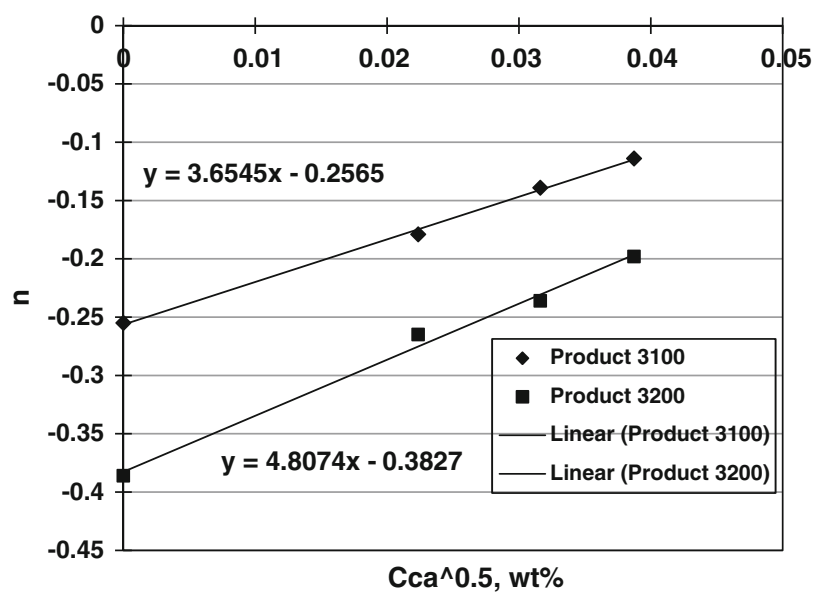

Fig. 7 Relationship between $\mathrm{CaCl}_{2}$ concentration and parameter $n$

It can be seen that the parameter $k$ is depressed at high salinity, while the parameter $\mathrm{n}$ slightly increases at elevated salinity. These trends are similar to those in Figs. 4, 5. The generalized relationship can be expressed as Eqs. (4), (5), where $b, b 1, \beta$, and $\beta 1$ are all empirical parameters. 
$\ln (k)=b \times\left(C_{\mathrm{Ca}}\right)^{1 / 2}+b 1$

$n=\beta \times\left(C_{\mathrm{Ca}}\right)^{1 / 2}+\beta 1$

In a previous paper (Gao 2013), the following equations were proposed to correlate the power-law parameters with polymer concentration $(\mathrm{PC}, \mathrm{ppm})$ and temperature $\left(\mathrm{T},{ }^{\circ} \mathrm{C}\right)$, where $c, c 1, d, d 1, \lambda, \lambda 1, \omega, \omega 1$ are all empirical parameters.

$\ln (k)=c \times \ln (\mathrm{PC})+c 1$

$\ln (k)=d \times T+d 1$

$n=\lambda \times \ln (\mathrm{PC})+\lambda 1$

$n=\omega \times T+\omega 1$

Combining Eqs. (2), (4), (6), and (7), the following formula is obtained, where $e$ is an empirical parameter:

$$
\begin{aligned}
\ln (k)= & a \times \ln \left(C_{\mathrm{Na}}\right)+b \times\left(C_{\mathrm{Ca}}\right)^{1 / 2}+c \times \ln (\mathrm{PC})+d \\
& \times T+e
\end{aligned}
$$

Combining Equations (3), (5), (8), and (9), the following formula is obtained, where $\varepsilon$ is an empirical parameter:

$n=\alpha \times \ln \left(C_{\mathrm{Na}}\right)+\beta \times\left(C_{\mathrm{Ca}}\right)^{1 / 2}+\lambda \times \ln (\mathrm{PC})+\omega \times T+\varepsilon$

Based on the test data in this paper and in a previous paper (Gao 2013), the empirical values are obtained with
Levenberg-Marquardt method. For the HPAM product with molecular weight of 10 million Dalton, the formulas are given in Eqs. (12), (13):

$$
\begin{aligned}
\ln (k)= & -0.63 \times \ln \left(C_{\mathrm{Na}}\right)-42.457 \times\left(\mathrm{C}_{\mathrm{Ca}}\right)^{1 / 2}+1.848 \\
& \times \ln (\mathrm{PC})-0.02 \times T-12.582 \\
n= & 0.068 \times \ln \left(C_{\mathrm{Na}}\right)+3.984 \times\left(C_{\mathrm{Ca}}\right)^{1 / 2}-0.143 \\
\times & \ln (\mathrm{PC})+6.944 \times 10^{-4} \times T+1.115
\end{aligned}
$$

For the HPAM product with molecular weight of 20 million Dalton, the formulas are presented in Eqs. (14), (15):

$$
\begin{aligned}
\ln (k)= & -0.631 \times \ln \left(C_{\mathrm{Na}}\right)-42.169 \times\left(C_{\mathrm{Ca}}\right)^{1 / 2}+2.094 \\
& \times \ln (\mathrm{PC})-0.016 T-13.713 \\
n= & 0.032 \times \ln \left(C_{\mathrm{Na}}\right)+4.743 \times\left(C_{\mathrm{Ca}}\right)^{1 / 2}-0.192 \\
\times & \ln (\mathrm{PC})+6.313 \times 10^{-4} T+1.208
\end{aligned}
$$

These formulas are then validated against the test data. The $k$ and $n$ values are calculated with these formulas and compared with the respective values obtained from experimental data, as presented in Tables 1, 2, 3 and 4. It can be seen that the calculated data match the test data relatively well. The advantage of these formulas is that the effects from all known factors are considered, while the previous models failed to include these influences (Zheng et al. 2000).
Table 3 Power law parameters for tests at different polymer concentrations

\begin{tabular}{lcccccc}
\hline Polymer product & $C \mathrm{p}(\mathrm{ppm})$ & $T\left({ }^{\circ} \mathrm{C}\right)$ & $k$ (tested) & $k$ (calculated) & $n$ (tested) & $n$ (calculated) \\
\hline \multirow{2}{*}{3,100} & 500 & 30 & 4.28 & 3.70 & -0.077 & -0.069 \\
& 1,000 & & 11.33 & 13.26 & -0.160 & -0.0169 \\
& 2,000 & & 42.64 & 47.74 & -0.257 & -0.268 \\
& 3,000 & & 123.81 & 101.00 & -0.339 & -0.326 \\
3,200 & 500 & 30 & 6.45 & 6.09 & -0.123 & -0.117 \\
& 1,000 & & 24.35 & 26.00 & -0.244 & -0.250 \\
& 2,000 & & 103.20 & 110.96 & -0.390 & -0.383 \\
& 3,000 & & 275.94 & 259.36 & -0.480 & -0.461 \\
\hline
\end{tabular}

Table 4 Power law parameters for tests at different temperatures

\begin{tabular}{lllllll}
\hline Polymer product & $C \mathrm{p}(\mathrm{ppm})$ & $T\left({ }^{\circ} \mathrm{C}\right)$ & $k$ (tested) & $k$ (calculated) & $n$ (tested) & $n$ (calculated) \\
\hline \multirow{2}{*}{3,100} & 2,000 & 50 & 28.90 & 28.95 & -0.260 & -0.250 \\
& & 70 & 19.00 & 19.40 & -0.233 & -0.236 \\
& & 90 & 14.00 & 13.01 & -0.220 & -0.294 \\
3,200 & 50 & 73.70 & 74.38 & -0.373 & -0.367 \\
& \multirow{2}{*}{2,000} & 57.42 & 54.00 & -0.360 & -0.355 \\
& & 30 & 39.43 & 39.22 & -0.331 & -0.342 \\
\hline
\end{tabular}




\section{Conclusion}

This paper presents the test data for HPAM viscosity in sodium chloride and calcium chloride solutions. It was observed that both monovalent and divalent ions have negative effects on HPAM viscosity. Data analysis shows that for the two HPAM products tested, the related powerlaw parameters are strong functions of water salinity and hardness.

This paper also presents a novel approach to model viscosity of HPAM solution. Previous models are failed to incorporate the factors that influence polymer viscosity. The proposed empirical correlations quantify the effects of salinity, hardness, temperature, and polymer concentration on HPAM viscosity. In future work, these correlations can be employed by pore-network model to study the polymer viscosity in macroscopic porous media.

Open Access This article is distributed under the terms of the Creative Commons Attribution License which permits any use, distribution, and reproduction in any medium, provided the original author(s) and the source are credited.

\section{References}

Gao C (2011) Scientific research and field applications of polymer flood in heavy oil recovery. J Petroleum Explor Prod Technol $1(2): 65-70$
Gao C (2013) Viscosity of partially hydrolyzed polyacrylamide under shearing and heat. J Pet Explor Prod Technol. doi:10.1007/ s13202-013-0051-4

Littmann W (1988) Polymer flooding. Elsevier, London, pp 3-4

Maerker JM (1975) Shear degradation of partially hydrolyzed polyacrylamide. SPE J 15(4):311-322

Mungan H (1972) Shear viscosity of ionic polyacrylamide solutions. SPE J 12(6):469-473

Needham R, Doe P (1987) Polymer flooding review. J Petrol Technol 39(12):1503-1507

Rabia H (1985) Oil well drilling engineering principles and practice. Graham \& Trotman, London, pp 96-98

Ryles RJ (1988) Chemical stability limits of water soluble polymers used in oil recovery processes. SPE Reserv Eng J 3(1):23-34

Sheng J (2010) Modern chemical enhanced oil recovery. Gulf Professional Publishing, Houston, Texas, pp 101-102

Sochi T (2009) Single-phase flow of non-Newtonian fluids in porous media. Thesis of University College London, London, UK, pp 8-11

Wang D, Dong H, Lv C, Fu X, Nie J (2009) Review of practical experience by polymer flooding at Daqing. SPE Reserv Eval Eng 12(3):470-476

Ward JS, Martin FD (1981) Prediction of viscosity for partially hydrolyzed polyacrylamide solutions in the presence of calcium and magnesium ions. SPEJ 21(5):623-631

Zheng CG, Gall BL, Gao HW, Miller AE, Bryant RS (2000) Effects of polymer adsorption and flow behaviour on two phase flow in porous media. SPE Reservoir Eval Eng 3(3):216-222 